\title{
Investigating the Effects of Monetary and Fiscal Policy on economic Growth in ASEAN: A Threshold Modelling Approach
}

\begin{abstract}
Siti Fatimah Ismail ${ }^{1}$ and Siok Kun Sek ${ }^{2}$
1, 2 School of Mathematical Sciences, Universiti Sains Malaysia, 11800 USM Penang, Malaysia

In the economic theory, many arguments from the different school of thoughts have been raised to justify the efficiency of economic policy in the view of stabilization. For instance, the correlation between macroeconomic variables and economic performance is a contentious issue. In this paper, we carefully examine and compare the impacts of fiscal (government expenditure) versus monetary policy (broad money and real interest rate) on economic growth using nonlinear regression. In particular, the main objectives include (1) to model the nonlinear threshold effect of broad money in modelling the economic growth by considering the 1997 Asian financial crisis influences and (2) to compare the impacts of both policies on economic growth. The study is based on a panel of ASEAN5 countries for the period of 19952015. Panel threshold regression established by Hansen (1999) was employed. The results reported a single threshold effect of broad money on inflation before and after controlling the crisis on determining economic growth. Here we observed that monetary policy through real interest rate caused to lower GDP growth while broad money led to the trade-off between inflation and growth. When broad money is high (above the threshold value), it led to higher economic growth but was compensated with the trade-off cost of higher inflation. Also, the Asian financial crisis caused to the significant drop in economic growth in ASEAN5. Overall, the study reported inefficient fiscal policy and monetary policy in the case of ASEAN countries.
\end{abstract}

Keywords: economic growth; monetary policy; fiscal policy; threshold effects

\section{INTRODUCTION}

For ages, the question about the effectiveness of fiscal and monetary policy as a main tool of the economy has become popular among economists especially in the scientific research. Some school of thoughts believed that fiscal policies can have positive effects on the economic growth while for others, the economy is always in a good and balanced situation. On the other hand, fiscal policy will have no effect or detrimental the economy. In contrast, monetarists believed that by increasing the circulation of money it will help the economy momentum to be more vibrant and it will deter the sluggish economic condition.
Nevertheless, it is known that both policies can be coexisting in the economy by putting forward the nonlinear character of fiscal and monetary policy in the economy growth. While linear models have been widely used in empirical studies, however, specific issues of economic data remain unexplained. This is because the behaviour of many economic crises or incidents which vary quite dramatically. Brooks (2014) stated that the economic behaviour may either alters suddenly which is known as a structural break or may vary for a period of time before either it returns back to its original position or changes to another behaviour namely, as a regime switching. Recently, there has been a huge amount of interest of non-linear models. In particular, the regime switching, or state dependent variable model has become the most prominent.

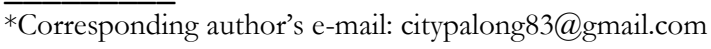


There are bulks of arguments regarding non-linear relationships between macroeconomic variables and economic growth. For example, Barro (1999) stated that the effect of highest government spending and taxation on the economic depends on the size of the government, suggesting a positive net effect if the government size is small. It indicates the existence of an optimal or growth maximizing level for the government size. Furthermore, some empirical studies proposed the non-linear correlation between the government size and economic growth portrayed as an inverted U-shaped curve or called Armey curve. The inverted U shaped was popularized by Armey (1995).

Motivated by these facts, this study examines generally the non-linear relationship between various macroeconomic variables and economic growth. In this study, we captured the threshold effects from monetary and fiscal variables on economic growth before and after controlling the 1998 financial crisis. Besides that, we compared the influences of fiscal versus monetary policy on determining the economic performance.

\section{A. A Review on the Economies in ASEAN Countries}

Historical data showed that ASEAN countries exhibiting high and stable GDP growth for about three decades (1970-1996) prior to the financial crisis of 1997-98. Table I shows that the during the period of 1970-1996, the highest annual growth rate of the developing countries in ASEAN were 7 percent. In 1998, most of the ASEAN countries went through recession after the crisis hit Thailand in 1997. The financial crisis affected four countries namely; Indonesia, Malaysia, the Philippines, and Thailand with the average rate of growth were -7.5 percent in 1998. Economic recession, especially in the crisis-affected countries experienced high inflation and rising of unemployment rate.

Table 1. GDP Growth rates in selected ASEAN countries (\%)

\begin{tabular}{|l|c|c|c|c|}
\hline Country & $1970-1996$ & 1996 & 1997 & 1998 \\
\hline Thailand & 7.5 & 5.5 & -1.3 & -10.0 \\
Indonesia & 6.8 & 8.0 & 4.5 & -13.7 \\
Malaysia & 7.4 & 8.6 & 7.5 & -7.5 \\
Philippines & 3.6 & 5.8 & 5.2 & -0.5 \\
Singapore & 8.2 & 7.6 & 8.4 & 0.4 \\
\hline
\end{tabular}


analysed the relationships among GDP, interest rate, CPI and inflation rates by using regression analysis for Pakistan in the period of 2000- 2011. The study observed that CPI and interest rate had a significant impact on GDP and inflation rate. Mohammad et. al., (2009) conducted studies to find out the long run relationship between M2, inflation, government expenditure impact and economic growth in Pakistan. The results reported a negative relation between public expenditure and inflation where they claimed that most of the public expenditure is non-development and inflation is due to adverse supply shock or cost push inflation in case of Pakistan. Yan and Gong (2009) studied the effect of fiscal policy on economic growth. They claimed that the taxation structure and government expenditure would affect the longrun growth through three medium such as household's choice, saving-consumption choice and the percentage of government expenditure to GDP. They found that expenditure does not always have a positive effect on economic performance.

\section{MATERIALS AND METHOD}

\section{A. $\quad$ Sources of Data}

This study employs the panel data, consisting of the ASEAN5 countries (Indonesia, Malaysia, Philippine, Singapore and Thailand) over the period of 1995 - 2015. The data were collected from the World Development Indicators of the World Bank and Federal Reserve Bank of St. Louis (FRED). The details of the data are presented in Table 2.

Table 2. Variables, symbols and measurements

\begin{tabular}{|lcl|}
\hline Variables & Symbols & Measurements \\
\hline Inflation & inf & log CPI- log CPI (t-1) \\
Economic growth & gdp & GDP percapital \\
Government expenditure ge & \% ofGDP \\
Broad money & bm & \% ofGDP \\
Real interest rate & ri & $\%$ \\
\hline
\end{tabular}

\section{B. Econometric Methodology}

Threshold regression models have developed rapidly over the three decades started with the seminal work of Tong (1983). Economic relationships may change subject to structural breaks or switching regimes. To handle this, threshold regression models have been developed. However, due to the important issues of unknown structural breakpoint and asymmetric behaviour of variables in different regimes, econometricians recognized that in addition to time, other variables may cause a structural change that is called threshold variables. In this section we used Hansen (1999) to search multiple regimes in the data using broad money (BM) as a possible threshold variable. The advantage of Hansen methodology based on an asymptotic distribution. Since the data series are in panel form, we employ panel unit root test to determine whether the variables are stationary. Panel unit root tests were employed and tested. These tests are used to test the null hypothesis of unit root. After confirming that all variables are stationary, the threshold autoregressive model developed by Hansen (1999) is estimated. To test for the existence of a threshold effect of broad money on economic growth, the following model is estimated:

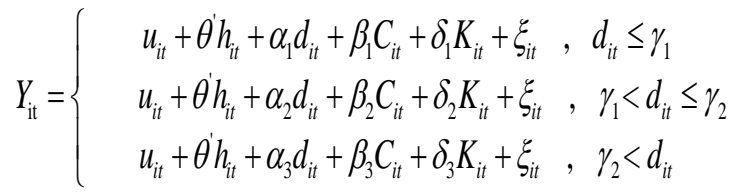

$$
\begin{aligned}
& \theta=\left(\theta_{1}, \theta_{2}, \theta_{3}\right)^{\prime} h_{i t}=\left(G E_{i t}, R I_{i t}, B M_{i t}\right) \\
& \xi_{i t} \sim \operatorname{iid}\left(0, \sigma^{2}\right)
\end{aligned}
$$

where $Y_{i t}$ represents economic growth (GDP), $d_{i t}$ ( broad money) is the threshold variable and $h_{i t}$ the explanatory variable, $\mathrm{C}$ is the 1998 financial crisis or dummy variable, $\mathrm{K}$ is the interaction effect between government expenditure and financial crisis, $u_{i t}$ is the fixed effect that represents the heterogeneity of countries under different policies and $h_{i t}$ are the explanatory variables which may affect economic performance. $\theta_{1}, \theta_{2}, \theta_{3}$ are the coefficient estimates of the explanatory variable (government expenditure, GE, real interest rate, $\mathrm{RI}$ and broad money), $\alpha_{1}$ is the threshold coefficient when the threshold value $\leq \gamma_{1} ; \alpha_{2}$ is the threshold coefficient when the threshold value $>\gamma_{1}$ but $\leq$ $\gamma_{2}$ and $\alpha_{3}$ is the threshold coefficient when the threshold value $>\gamma_{2} ; \beta_{1}, \beta_{2}, \beta_{3}$ represent the coefficient estimates of the dummy variable, $\mathrm{C}$ while $\delta_{1}, \delta_{2}, \delta_{3}$ represent the coefficient estimates of the interaction effect, K. The error $\xi_{i t}$ are assumed to be independent, identically distributed 
(i.i.d), with mean zero and finite variance $\sigma^{2}\left(\xi_{i t} \sim\right.$ i.i.d. $\left.\left(0, \sigma^{2}\right)\right), i$ represents different countries and $t$ represents different periods. It is important to determine whether threshold effect is statistically significant or not. Hansen (1999) suggested a bootstrap to simulate the asymptotic distribution of threshold estimate. Using the two-stage ordinary least squares (OLS) method and minimizing the sum of squares of errors, $S_{1}(\gamma)$, the estimators of the threshold value and the residual variance $\hat{\gamma}$ and $\hat{\sigma}^{2}$ can be obtained. The null hypothesis of no threshold effect is tested, $H_{0}: \alpha_{1}=\alpha_{2}$, using the likelihood ratio test $F_{1}=\frac{\left(S_{0}-S_{1}(\hat{\gamma})\right)}{\hat{\sigma^{2}}}$ where $S_{0}$ and $S_{1}(\hat{\gamma})$ are sum of squared error for null hypothesis and alternative hypothesis, respectively. Since then $F_{1}$ has non-standard distribution, Hansen (1999) showed that bootstrap procedure will construct $p$-values and critical values that are asymptotically valid. When the alternative hypothesis holds, $H_{1}: \alpha_{1} \neq \alpha_{2}$ it shows that there is a threshold effect between broad money and economic growth. Thus, the asymptotic distribution of threshold estimate is tested with the null hypothesis, $H_{0}: \gamma=\gamma_{0}$, using the likelihood ratio statistics test of $L R_{1}(\gamma)=\left(S_{1}(\gamma)-S_{1}(\hat{\gamma})\right) / \hat{\sigma^{2}}$. The asymptotic confidence interval is shown as $c(\alpha)=-2 \log (1-\sqrt{1-\alpha})$ where for a given asymptotic level $\alpha$, the null hypothesis of $H_{0}: \gamma=\gamma_{0}$ is rejected if $L R_{1}(\gamma)$ exceeds $c(\alpha)$.

\section{RESULTS AND DISCUSSIONS}

\section{A. $\quad$ Panel Unit Root Tests}

Panel unit root tests in Table 3 shows that all variables are stationary at levels, I(o) since the nulls hypothesis of unit root were rejected at $1 \%$ level except for $\mathrm{GE}$ and $\mathrm{BM}$ which are rejected at $5 \%$ level of significance. This allows further analysis of the panel threshold regression.
Table 3. Panel unit root tests

\begin{tabular}{|l|l|l|}
\hline Variables & t-stat & $\begin{array}{l}\text { Level of } \\
\text { integration }\end{array}$ \\
\hline GDP & $-6.32(0.00)$ & I (o) \\
INF & $-6.58(0.00)$ & I (o) \\
BM & $-2.19(0.01)$ & I (o) \\
GE & $-1.76(0.04)$ & I (o) \\
RI & $-6.86(0.00)$ & I (o) \\
\hline
\end{tabular}

Note: The numbers in bracket represent p-values.

\section{B. Tests for Threshold Effects}

Table 4 reports the results of F-statistics for single, double and triple threshold effects before and after the 1998 financial crisis together with their bootstrap p-values. We applied 300 bootstrap replications for ach three bootstrap tests. The statistics F1 which refer to the test for single threshold effect before controlling the crisis is significant at 5 per cent level since it is higher than the critical value of 14.487. However, the $\mathrm{F}$ statistics for double and triple threshold are insignificant with the bootstrap p-value 0.4433 and 0,2367 respectively. Similarly, after controlling the crisis, the results show that F-statistics for single threshold is significant at 1 per cent whilst for double and triple threshold are considered as statistically not significant at 10 per cent level. Hence, we conclude that there is evidence of a single threshold effect of broad money on economic growth conditioned by inflation before and after controlling the crisis. Henceforth, we focus on the single threshold model for the rest of the estimation results.

Table 4. Test for threshold effects before and after controlling the crisis

\begin{tabular}{|l|l|l|}
\hline & $\begin{array}{l}\text { Before controlling } \\
\text { the crisis }\end{array}$ & $\begin{array}{l}\text { After controlling } \\
\text { the } \\
\text { crisis }\end{array}$ \\
\hline Test for single & & \\
\hline threshold & & 8.52 \\
\hline F1 & 16.31 & $0.007^{* * *}$ \\
\hline p-value & $0.010^{* *}$ & $(5.41,6.49,7.60)$ \\
\hline (10\%,5\%,1\% & $(8.12,10.01,14.49)$ & \\
\hline critical values) & & \\
\hline Test for double & & 1.32 \\
\hline threshold & & 0.42 \\
\hline F2 & 3.19 & \\
\hline p-value & 0.44 & \\
\hline
\end{tabular}




\begin{tabular}{|l|l|l|}
\hline$(10 \%, 5 \%, 1 \%$ & $(7.41,9.77,14.87)$ & $(8.57,10.40,13.61$ \\
& & \\
\hline critical values) & & \\
\hline Test for three & & \\
\hline threshold & & 2.57 \\
\hline F3 & 3.69 & 0.49 \\
\hline p-value & 0.24 & $(8.57,10.40,13.61$ \\
\hline (10\%,5\%,1\% & $(10.98,15.92,24.78)$ & ) \\
\hline critical values) & & \\
\hline & & \\
\hline
\end{tabular}

Note: The asterisks $\left({ }^{* * *}\right),\left(^{* *}\right)$ and $\left({ }^{*}\right)$ denote the

statistically significant at $1 \%, 5 \%$ and $10 \%$ levels

respectively.

Table 5. Threshold estimate for broad money before and after controlling the crisis

\begin{tabular}{|l|l|c|}
\hline & $\begin{array}{l}\text { Before } \\
\text { controlling the } \\
\text { crisis }\end{array}$ & $\begin{array}{l}\text { After } \\
\text { controlling the } \\
\text { crisis }\end{array}$ \\
\hline $\begin{array}{l}\text { Estimate, } \\
\gamma_{1}\end{array}$ & 58.90 & 58.90 \\
\hline $\begin{array}{l}95 \% \\
\text { confident } \\
\text { interval }\end{array}$ & {$[58.05 ; 59.00]$} & {$[56.70 ; 59.00]$} \\
\hline
\end{tabular}

It is shown in Table 5 that the estimated value of a single threshold before and after controlling the financial crisis is found to be 58.9 thus splitting all observation into two regimes.

\section{A. $\quad$ Estimated Coefficient Single Threshold Models}

Table 6 shows the result of the threshold estimation based on OLS standard errors before and after controlling 1998 crisis. The two coefficients of our main interest are those regression coefficients $\beta_{1}, \beta_{1}, \beta_{2}$, by each regime. The first regime's estimated coefficient before controlling the crisis is 1.1105 which is not significant at 10 percent. We can also note that when the broad money is less than or equal to the threshold of 58.9, inflation rate has no significant effect on economic growth. In other words, there is no relationship between inflation and economic growth when the broad money below the threshold level. However, in the second regime, the estimated coefficient is 32.29 which is significant at 1 percent level. The results indicate that when broad money is above the threshold level, inflation has a positive significant effect on economic growth. Apart from that, we can see that the real interest rate has negative significant effect on GDP growth. This implies that 1 percent increase in interest rate leads to lower GDP growth by 0.14 unit. In contrast, government expenditure and broad money are insignificant which implies that there is no relationship between both variables and economic growth before considering financial crisis. The result shows that monetary policy is not effective which higher interest rate leads to lower GDP growth. However, GDP may still show an increment but with lower rate. After controlling the crisis, the real interest rate and broad money have negative significant effect on economic growth. This implies that 1 per cent increase in the real interest rate and broad money will lead to lower GDP growth. Our findings corroborate with the findings of several studies such as Adusei (2013) who found that money supply undermined economic growth.

Similarly, there is negative significant effect of dummy variables on economic growth which implies that during the crisis period (1997-98), economic growth is 8.77 units lower than the non-crisis period. On the other hand, crisis has caused to very large drop ( -8.76 units) of GDP growth as compared to other macroeconomic variables. Our findings also reported no significant relationship between government expenditure and interaction (GE and crisis) with GDP growth. The dependent regimes switching shows that the first regime's estimated coefficient is -4.27 which is not significant at 10 percent. In other words, there is no relationship between inflation and economic growth when the broad money below the threshold level. However, in the second regime, the estimated coefficient is 17.18 which is significant at 1 percent. The results indicate that when broad money is above the threshold level, inflation has a positive significant effect on economic growth.

Table 6. Estimated coefficient single threshold model before and after controlling the crisis

\begin{tabular}{|l|l|l|l|l|}
\hline & Regressors & $\begin{array}{l}\text { Coefficient } \\
\mathrm{s}\end{array}$ & $\begin{array}{l}\text { Std. } \\
\text { Errors }\end{array}$ & t-stats \\
\hline Before & GE & 0.05 & 0.25 & 0.18 \\
& RI & -0.14 & 0.08 & $-1.79^{*}$ \\
& BM & -0.05 & 0.03 & 0.11 \\
& & & & \\
\hline
\end{tabular}




\begin{tabular}{|l|l|l|l|l|}
\hline & INF (BM $\leq$ & 1.11 & 5.94 & 0.19 \\
$58.9)$ & 32.29 & 4.40 & $7.33^{* *}$ \\
INF $(58.9<$ & & & \\
BM) & & & \\
\hline After & GE & -0.03 & 0.22 & 0.13 \\
& RI & -0.13 & 0.07 & $-1.86^{*}$ \\
& BM & -0.05 & 0.03 & $-1.97^{* *}$ \\
C & -8.77 & 1.67 & - \\
& K & 0.57 & 1.69 & $5.24^{* * *}$ \\
& INF (BM $\leq$ & -4.27 & 5.29 & 1.21 \\
& $58.9)$ & 17.18 & 5.29 & -0.81 \\
INF $(58.9<$ & & & $3.25^{* * *}$ \\
BM) & & & \\
\hline
\end{tabular}

\section{SUMMARY}

In this study, we focus our analysis on examining and comparing the impacts of fiscal policy versus monetary policy on economic growth using nonlinear regression. Applying the threshold regression analysis, we detected a single threshold estimate before and after controlling financial crisis and found that inflation has positive effect on growth when broad money exceeded the threshold level.

Overall, fiscal policy does not lead to significant economic growth. In contrast, monetary policy through real interest rate caused to lower economic growth while broad money led to the trade-off between inflation and growth. On the other hand, monetary policy is not effective to stimulate economic growth. When broad money is high or above the threshold value, it led to higher economic growth but was compensated with the trade-off cost of higher inflation. This study reported inefficient fiscal and monetary policy in the case of ASEAN countries.

\section{REFERENCES}

Adusei, M 2013, 'Financial development and economic growth: Evidence from Ghana', The International Journal of Business and Finance Research, vol.7, pp.61.

Armey, D (eds) 1995, The freedom revolution, Regnery Publishing, Washington DC.

Barro, RJ 1999, 'Government spending in a simple model endogenous growth', Journal of Political Economy, vol.98, no. 5 , pp.103-125.

Brooks, C, (eds) 2014, 'Switching models. Introductory econometrics for finance, 3rd edn, University Press, Cambridge, United Kingdom.

Grawe, PD \& Polan, M 2005, 'Is inflation always and everywhere a monetary phenomenon?', Scandinavian Journal of Economics, vol.107, pp.239-259.

Hansen B, 1999, 'Threshold effect in non-dynamic panels: Estimation, testing and inference', Journal of econometrics, vol.93, pp.345-368.

Ihsan, I \& Anjum, S 2013, 'Impact of money supply (M2) on
GDP of Pakistan', Global Journal of Management and Business Research Finance, vol.13.

Lee, KS \& Werner, RA 2018, 'Reconsidering monetary policy: an empirical examination of the relationship between interest rates and nominal GDP growth in the U.S., U.K., Germany and Japan', Journal of Ecological Economics, vol. 146, pp.26-34.

Mohammad SD, Wasti SK, Lal I \& Hussain A 2009, 'An empirical investigation between money supply, government expenditure, output \& prices: the Pakistan Evidence', European Journal of Economics, Finance and Administrative Sciences, Issue17.

Tong, H 1983, 'Threshold models in non-linear time series analysis', 1st edition, Springer Publisher, New York.

Wimanda, RE 2011, 'The impact of exchange rate depreciation and the money supply growth on inflation: The implementation of threshold model', Bulletin of Monetary, Economic and Banking, Indonesia.

Yan, C \& Gong, L 2009, 'Government expenditure, taxation and long-run growth', Frontiers of Economic in China, Economic. 